\title{
Performance of Water Supply Lines in a Post-Earthquake Scenario
}

\author{
Mohd Abul Hasan* \\ Civil Engineering Department, College of Engineering, King Khalid University, \\ PO Box 394, Abba - 61421, Kingdom of Saudi Arabia
}

Received: 3 February 2021

Accepted: 15 March 2021

\begin{abstract}
An earthquake can affect a vast category of buried lifelines performance such as water distribution system, sewage disposal system, petroleum enterprises, etc. In the present study, damage in terms of performance and working of water distribution system after severe earthquakes in a metropolitan city is assessed to develop serviceability priorities. A system simulation based on Kameda's model is also developed for obtaining useful information on the behavior of the water supply system in the pre-and post-earthquake scenario. The event modeled is the earthquake that is believed to produce extensive losses to life and property. The priorities strategy for rehabilitation of buried water distribution system is framed considering important factors such as damage in terms of leakage, reliable water demand after earthquake damage, and water distribution path length. In this study, repair management is applied systematically to restore the reliable water supply in a water distribution path. The recommendations are framed and priority of repair of the water distribution system of various paths of city zone is established such as pre-assuming a post-earthquake scenario, from the case study of one of the most important metropolitan cities of Asian country i.e., Delhi.
\end{abstract}

Keywords: seismic damage, simulation model, sustainable water supply network, system restoration, damage assessment

\section{Introduction}

Lifelines are engineering networks that have a vital impact on the urban lifestyle [1]. Components of lifeline system comprise of many such as water distribution system, sewerage system, gas distribution system, telecommunication system, roadways and railways including bridges and tunnels. A review of past post-

*e-mail:mohad@kku.edu.sa earthquake scenarios has revealed that earthquakes can cause extensive damage to lifeline systems [2]. The planning to handle the malfunctioning and chaotic situation of any lifeline system should be made before the occurrence of the disaster [3]. The damage to the lifeline system not only interrupts the function of essential service to the public but also interfere with the rescue efforts during and after an earthquake. During recent years, major earthquakes have struck quite frequently all around the globe even in the seismically non-active zones. The global climatic change may be a possible cause for increasing trends of earthquake 
occurrence [4]. The major earthquakes and disaster effects that occurred in the past few years around the world are reviewed in the literature. Latur (India) earthquake in 1993 which had a magnitude of 6.4 (on Richter scale), killed 10,000 people and heavy damage to lifelines [5]. The Cabinet Office, Government of Japan [6] released details of the 1995 Kobe (Japan) earthquake, which had a magnitude of 7.2 (on Richter scale) with 6437 fatalities and missing persons and seriously damaged major lifelines such as bridges, roads, and subways, Sichuan (China) earthquake in 2008 which had a magnitude of 7.9 (on Richter scale), claimed 80,000 lives and damage to infrastructures due to landslides and soil liquefaction [7], Ludian (China) in 2014 which had a 6.1-magnitude (on Richter scale) claimed 600 lives and damage to lifelines and property, Kathmandu (Nepal) in 2015 with 7.8-magnitude (on Richter scale) earthquake killed 9,000 people and severely damaging lifeline system [8] Chiapas (Mexico) 8.2-magnitude (on Richter scale) earthquake in 2017 with 61 persons killed and large scale destruction due to landslides [9]. Recently, many studies have been performed based on post earthquake scenario like performance assessment of Salyankot water supply project in nepal [10], risk-based assessment of infrastructure system [11, 12], firefighting capacity evaluation of water distribution system [13], collective action in post-earthquake Nepal [14], estimation of restoration time of power and telecommunication lifelines [15], assessment of functionality of buildings [16], restoration of water system using discrete-event simulation [17].

Because of the frequent occurrence of high magnitudes earthquake and consequent damage to the environment and lifelines, such as the water supply system, it is, therefore, necessary to develop sustainable restoration systems and risk reduction management to lifelines.

Several methods and analysis procedures have been developed for various lifelines component damage simulation in the post-earthquake scenario. An earthquake can affect a vast category of lifelines, present work is confined to evaluate the performance of a very essential component of lifeline, i.e., water distribution system under the impact of a severe earthquake. Lifeline damage not only disrupts the distribution of essential services to the public but also interferes with rescue efforts during and after the earthquake. Various studies have quantified the earthquake damage to the water supply network [18,19]. Zohra et al. [20] have evaluated the seismic vulnerability of existing lifeline network facilities considering the identification of the parameters that have an influence on the behavior of pipelines network and seismic vulnerability classification of lifeline network facilities based on safe, unsafe, and an intermediate situation are implemented on Geographical Information System (GIS) platform.

The relationship of pipeline risk for ground shaking (transient ground deformation) in several different earthquake scenarios is assessed by Torpak and Taskin [21]., Liu et al. [22] have developed a decisionmaking support framework for the restoration of wastewater systems in the post-earthquake scenario to assess physical damage, assess functionality, and predict recovery time. These studies quantified the serviceability of water supply systems in the event of seismic damage, but no post-event simulation applications were provided.

Yoo et al. [23], Kang et al. [24] introduced the model developed for domestic water supply networks to assess seismic reliability and suggested an ideal model of pipe diameter. Chang et al. [25] suggested that pipe repair times for broken pipes using an empirical formula derived using the data from the Korea Water Resources Corporation (K-water) field. Whitman and Hein [26] and Hall and Newmark [27] conducted studies on earthquake risk quantification reflecting the hydraulic features of water supply facilities. Yoo [28] subsequently conducted quantification studies of earthquake damage related to hydraulic analysis on pipe networks. Recently, Davis et al. [29] subdivided a water pipe network's serviceability into several variables such as water supply, quality, quantity, fire safety, and functionality. In this, they referred to each item's quantified recovery phases and analyzed the phases by comparing them with the recovery phase of the Northridge earthquake. Klise et al. [30, 31] developed a WNTR (Water Network Resilience Tool) which is an open-source Python package that assists water supply plants to explore water serviceability (WSA) and recovery time for each earthquake scale, place, and hydraulic method. Yoo G. [28] quantified the water supply system's serviceability during an earthquake and suggested optimal design steps to strengthen the system. This study quantified the water supply systems' serviceability under seismic damage, but there were no applications for the simulation for post-event restoration. As per the theoretical and conceptual framework drawn from the above-mentioned literature review, there is a research gap in quantified serviceability of water supply systems under seismic damage in the post-earthquake restoration simulation. In this paper, the functional reliability of the water distribution system under a post-earthquake scenario for a metropolitan city, Delhi, is provided and repair management is applied to effectively restore the damaged water distribution system.

\section{Material and Methods}

\section{Study Area}

The National Capital Territory-Delhi (NCT-Delhi) is geographically situated between $28^{\circ} 23^{\prime} 17^{\prime \prime}$ to $28^{\circ} 53^{\prime} 00^{\prime \prime}$ North latitudes and $76^{\circ} 50^{\prime} 24^{\prime \prime}$ to $77^{\circ} 20^{\prime} 37^{\prime \prime}$ East longitudes. It lies at an elevation between 213 and $305 \mathrm{~m}$ and covers an area of $1,483 \mathrm{~km}^{2}$. As per the primary census abstract 2011, the population of Delhi 
is 16.79 million. The projection was nearly correct and with the average growth rate since the census of 1881 , the population would touch 20.347 million by 2021 . It is situated on the bank of the river Yamuna and lies in Seismic Zone IV of the Seismic Zoning Map of India. Geologically, Delhi is located on a folded crustal ramp with basement rocks of Delhi Supergroup, bounded by two regional faults viz. the western fault in Mahendragarh-Dehradun and the Eastern Great Border Fault. Syed Emad et al. [32] Earthquakes from far-field seismic sources in the Himalayas have affected Delhi and its surroundings. Fig. 1 shows the geology and lineaments map of NCT-Delhi along with the first level seismic hazard micro-zonation map prepared by Shukla et al. [33].

\section{Preparation of the Network Model}

The network model of the water distribution system in a post-earthquake scenario of an important metropolitan city of an Asian country i.e., NCT-Delhi is framed. All regions of NCT are fed by four waterworks, supplying a total of 1297 million liters per day (MLD) of water and the total area is divided into thirteen zones by the Municipal Corporation of Delhi. The basic flow network to study the system performance and reliability has been prepared for New Delhi Zone. The network of mains with various nodes is shown in (Fig. 2). The performance of the water distribution system for different parameters studied i.e., water demands, water supply and required water supply, etc.

The analysis performed for New Delhi Zone can similarly be extended to other zones. The user population of this zone is estimated at around 300,000 .
A total of 123 MLD of water is supplied to this zone with a normal water supply of 135 liters per day per person. The New Delhi Zone has been further subdivided into six sub-network paths to facilitate the versatility of the model. The numbered circles represent the branch nodes. Each branch node distributes the water supply to the corresponding sub-network of a branch distribution system. The flow rate on each node is examined. Based on the serviceability parameters of the New Delhi Zone, the flow of 123 MLD is subdivided into six sub-network paths. Sub-network path 1 has a total discharge of $85,000 \mathrm{~m}^{3} /$ day which is further subdivided into three paths i.e., sub-network path number 2, 3, and 4 with this discharge. Sub-network path 5 has a discharge of $27,000 \mathrm{~m}^{3} /$ day and sub-network path 6 has a discharge of $11,000 \mathrm{~m}^{3} /$ day.

\section{Kameda Model}

To evaluate the performance and function of the water distribution system after the earthquake damage has occurred, the Kameda's Model [34], has been used. The performance, working, and behavior of the water distribution system, in the post-earthquake scenario of a selected urban city, have been assessed based on the information and primary data collected. The vulnerability and priority strategy i.e., which branch of the water supply system must be repaired on a priority basis are also assessed for each subzone. The repair priority of various zones will be decided by evaluation of the deference in normal demand and demand under a damaged state for a fixed water requirement.

The Kameda's Model [34], to evaluate the performance and functioning of water distribution

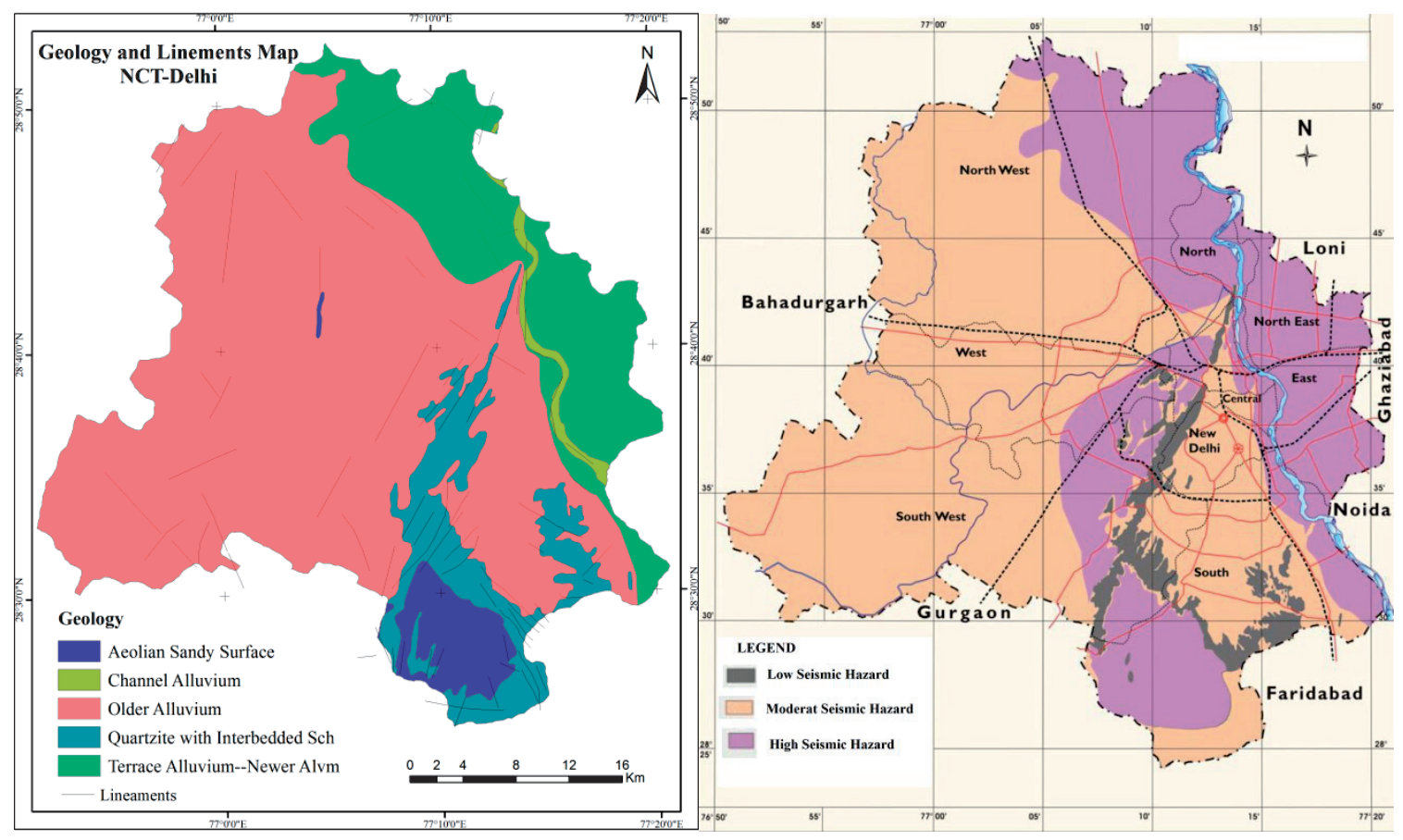

Fig. 1. Geology and lineaments map of NCT-Delhi; First level seismic hazard micro-zonation Map [33] of NCT-Delhi. 


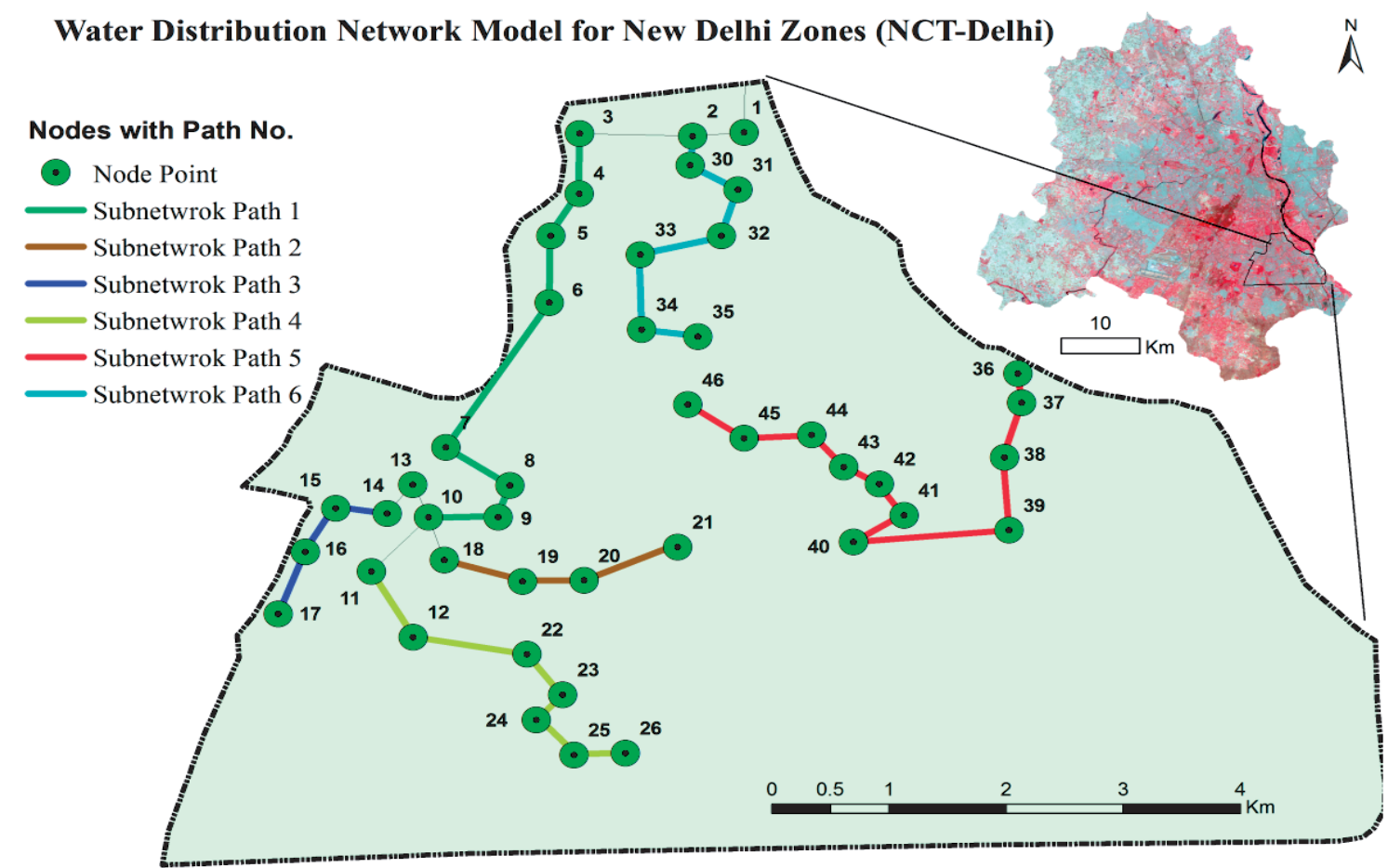

Fig. 2. Water distribution network model for New Delhi Zones (NCT-Delhi).

system after the earthquake damage in terms of leakage, has extensively been used to assess seismic damage, system reliability, and variation of serviceability during post-earthquake recoveries of water supply pipelines. Assessment of the system reliability and serviceability of water supply pipelines during and after strong earthquakes constitute a major part of lifeline earthquake engineering.

Kameda's model assumed the water supply-demand of the post-earthquake scenario into four typical stages. The minimum functional requirement for the water supply system may vary with each stage as given below. Stage 1: Supply for firefighting immediately after the earthquake.

Stage 2: Supply to critical locations like refuge zones, hospitals, etc.

Stage 3: Supply to support minimum daily lives during the restoration period

Stage 4: Normal supply with all restoration work completed.

Not all four stages need to be present in all damaging earthquakes as has been observed from the literature [34]. The fire hazard due to the earthquake is assumed to pose not a serious threat. Also, the minimum water supply can be achieved if the supply and demand nodes are connected by at least one of the alternative paths in the main distribution network as the functional reliability requirement for stage 2 . The functional reliability of urban life stages 1 and 2 can be excluded. During stage 3 citizens will return to their homes as far as possible. Repair work for the water supply system will start to achieve its goal i.e., stage 4. Therefore, the present work is confined to the functional requirement of stages 3 and 4 .

\section{Local Serviceability (Stage 3 \& 4)}

Local serviceability is represented in terms of the water flow rate supplied from a branch node to its dependent sub-network. Two parameters are used for this purpose, i.e., for branch node i, Expected supplydemand ratio ' $\mathrm{r}$ '

The expected supply-demand ratio ' $r$ ' ${ }_{\mathrm{qi}}$ is given by

$$
\mathrm{r}_{\mathrm{qi}}=\frac{1}{n s} \sum_{k=1}^{n s} Q i^{k} / P d i
$$

...where:

$\mathrm{ns}=$ number of repeated simulations

Pdi= water demand

Qi = actual consumption, from branch node, $\mathrm{i}$

Probability of demand satisfied ' $r$ '

The satisfaction of the probability of demand ' $r$ ' ${ }_{n i}$ is represented by ' $r$ ' ${ }_{n i}=$ (Numbers of simulation in which

$$
\mathrm{Qi}=\mathrm{Pdi} / \mathrm{ns})
$$

The expected supply-demand ratio ' $\mathrm{r}$ ' $\mathrm{qi}$ is the ratio of the expected actual consumption to the demand. The 
probability ' $r$ ' may be useful for a measure to be used by the supplier. There is a relation $r_{n i}<r_{\text {ii }}$ (Fig. 3) shows the value of $r_{n i}$ and $r_{\mathrm{qi}}$ for the specific branch node.

\section{Global Serviceability (Stage $3 \& 4$ )}

The required total supply per day, $\mathrm{W}_{\mathrm{t}}$ is represented as

$$
\mathrm{W}_{\mathrm{t}=\frac{1}{n s}} \sum_{k=1}^{n s} \sum_{i=1}^{n b}\left(Q i^{k}+L i^{k}\right) T
$$

$\mathrm{n}_{\mathrm{s}}=$ Number of repeated simulations

$\mathrm{n}_{\mathrm{b}}=$ Number of branch nodes

$\mathrm{Q}_{\mathrm{i}}=$ Actual consumption

$\mathrm{L}_{\mathrm{i}}=$ Leakage

$\mathrm{K}=$ stands for $\mathrm{K}^{\text {th }}$ simulation

$\mathrm{T}=$ Length of the day

If the value Wt exceeds the capacity of the supply plant, the system is unable to meet the demand until repair work reduces leakage to a certain level. Such conditions are shown in (Table 1) which compares Wt with different water demands for damaged and undamaged states.

\section{Results and Discussion}

\section{Performance of Water Distribution System}

To activate the various simulations, different intensity of leakage in the actual water supply is calculated for the corresponding discharge at various nodes. For different water demands, the required water supply $\left(W_{t}\right)$ is evaluated. The possibility of a system to meet out the demand for specific damage or loss percentage is assessed based on comparative values of required total supply, at a particular loss and the normal water demand.

It has been experienced from the earlier studies [34] that the extent of loss "during and after" earthquake stage varies in the diversified range i.e., from minimum to complete damage conditions. Hence to cater to the requirement of post-earthquake stages the discharge

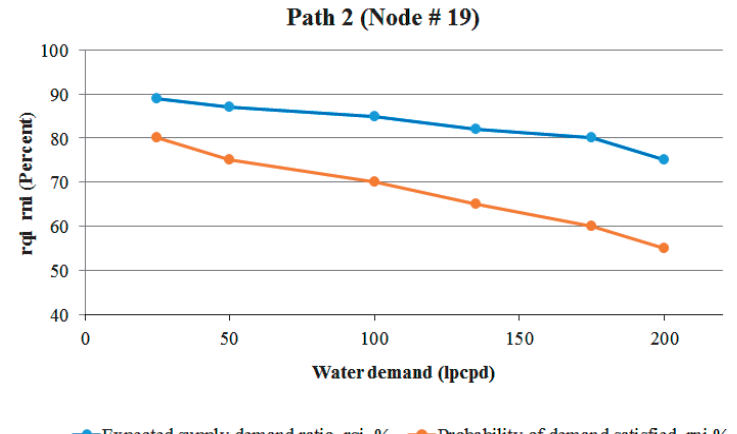

$\rightarrow$-Expected supply demand ratio, rqi \% $\rightarrow$-Probability of demand satisfied, mi \%

Path 6 (Node \# 31)

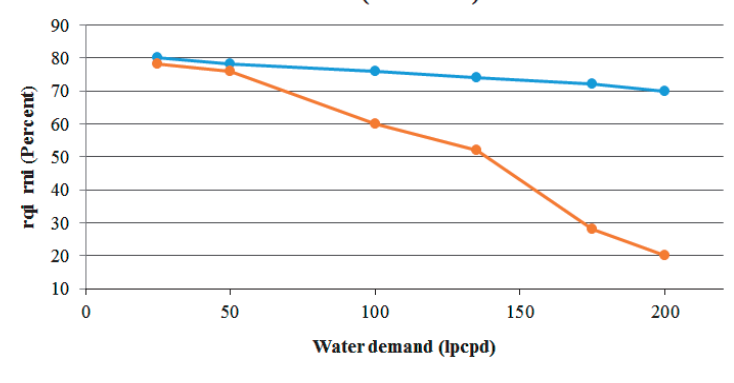

$\rightarrow$-Expected supply demand ratio, rqi $\% \rightarrow$-Probability of demand satisfied, rni $\%$

Fig. 3. Estimated local serviceability of sub-network path 2 (node 19) and sub-network path 6 (node 31).

losses have been simulated in terms of different percentages of actual supply. Different values of losses i.e., leakage $\left(\mathrm{L}_{\mathrm{i}}\right)$ are assumed as $15 \%, 30 \%, 50 \%, 80 \%$ of the actual supply of $Q_{i}$ and full damage condition $\left(100 \%\right.$ of $\left.Q_{i}\right)$. For different sub-network paths, the actual supply $Q_{i}$ and $W_{t}$ considering the various leakages and for a normal supply of 135 lpcpd are shown in Table 1.

\section{Estimated Local Serviceability:}

Local serviceability represented by the expected supply-demand ratio $\left(\mathrm{r}_{\mathrm{qi}}\right)$ and the probability of demand satisfied $\left(\mathrm{r}_{\mathrm{ni}}\right)$ is estimated for branch node 19 and node 31 of path 2 and 6 respectively. The values of $r_{n i}$ and $r_{q i}$ are plotted in Fig. 3. It is shown that the values of $r_{n i}$ and $\mathrm{r}_{\mathrm{qi}}$ are reducing with an increase in water demand under the damage condition.

Table 1. Various sub-network paths the actual supply, $Q_{i}$ and required water supply, $W_{t}$ for a normal demand of 135 lpcpd (liters per capita per day).

\begin{tabular}{|c|c|c|c|}
\hline Sub-network Path No & $\begin{array}{c}\text { Normal water demand for each } \\
\text { node, } \mathrm{m}^{3} / \mathrm{day}\end{array}$ & $\begin{array}{c}\text { Actual Supply } \\
Q i, \mathrm{~m}^{3} / \mathrm{day}\end{array}$ & $\begin{array}{c}\text { Required Supply } \\
W t, \mathrm{~m}^{3} / \mathrm{day}\end{array}$ \\
\hline 1 & 1000 & 85000 & 137068 \\
\hline 2 & 1000 & 6500 & 7144 \\
\hline 3 & 1000 & 6500 & 18430 \\
\hline 4 & 1000 & 14000 & 40100 \\
\hline 5 & 1000 & 27000 & 13743 \\
\hline 6 & 1000 & 11000 & \\
\hline
\end{tabular}




\section{Subnetwork Path Analysis}

The water distribution of the New Delhi Zone has been subdivided into six sub-network paths represented by sub-network paths $1,2,3,4,5$, and 6 . The serviceability requirement of the water distribution system for each sub-network path is assessed using Kameda's model [34].

For sub-network path 1 , having node numbers 3 , $4,5,6,7,8,9,10$ the required total supply per day, is calculated using equation number (3) given in the preceding section. Based on the first simulation, the required total supply is assessed for different water demands during and after the earthquake. To study the probability of water demand being satisfied under any damage condition of the pipeline, different water demands such as 25, 50, 100, 135, 175, 200 Liters per capita per day (lpcpd) are incorporated to activate various simulations. The methodology has been elaborated for evaluation for a specific sub-network path 1 for a demand of 25 lpcpd corresponding to the normal supply of $15741 \mathrm{~m}^{3} /$ day. Similarly, the required water supply can be evaluated for other demand values as well. The evaluated water supply for different water demands for a specific sub-network path 1 is shown in
Fig. 4. From this figure, it is observed that for a normal supply of $135 \mathrm{lpcpd}$, which is equivalent to a total demand of $85,000 \mathrm{~m}^{3} /$ day, the damaged system can meet only $80 \mathrm{lpcpd}$, which implies that the system needs an immediate repair to meet out the normal supply.

For sub-network path 2 which is branches from subnetwork path 1, have 4 nodes i.e., node numbers 18,19 , 20,21 , and node numbers $13,14,15,16$ of sub-network path 3 . The required water supply can be estimated, and other parameters used are also evaluated as has been shown in the earlier subsection. Results for sub-network path 2 and sub-network path 3 are plotted in Fig. 4. It is observed that for a normal supply of $135 \mathrm{lpcpd}$ which is equal to a total demand of $6,500 \mathrm{~m}^{3} /$ day, the damaged system can meet a supply of 120 lpcpd near $135 \mathrm{lpcpd}$, because sub-network path 2 and sub-network path 3 are the shortest ones. Hence the system does not need immediate repair to meet the normal supply.

For sub-network path 4 , which has node numbers $11,12,22,23,24,25$, and 26 is also separated from sub-network path 1 , the required water supply can be similarly evaluated as for sub-network path 1 . From Fig. 4, it is observed that for a normal supply of 135 lpcpd which is equal to a total demand of $1,4000 \mathrm{~m}^{3} /$ day. The damaged system can meet only
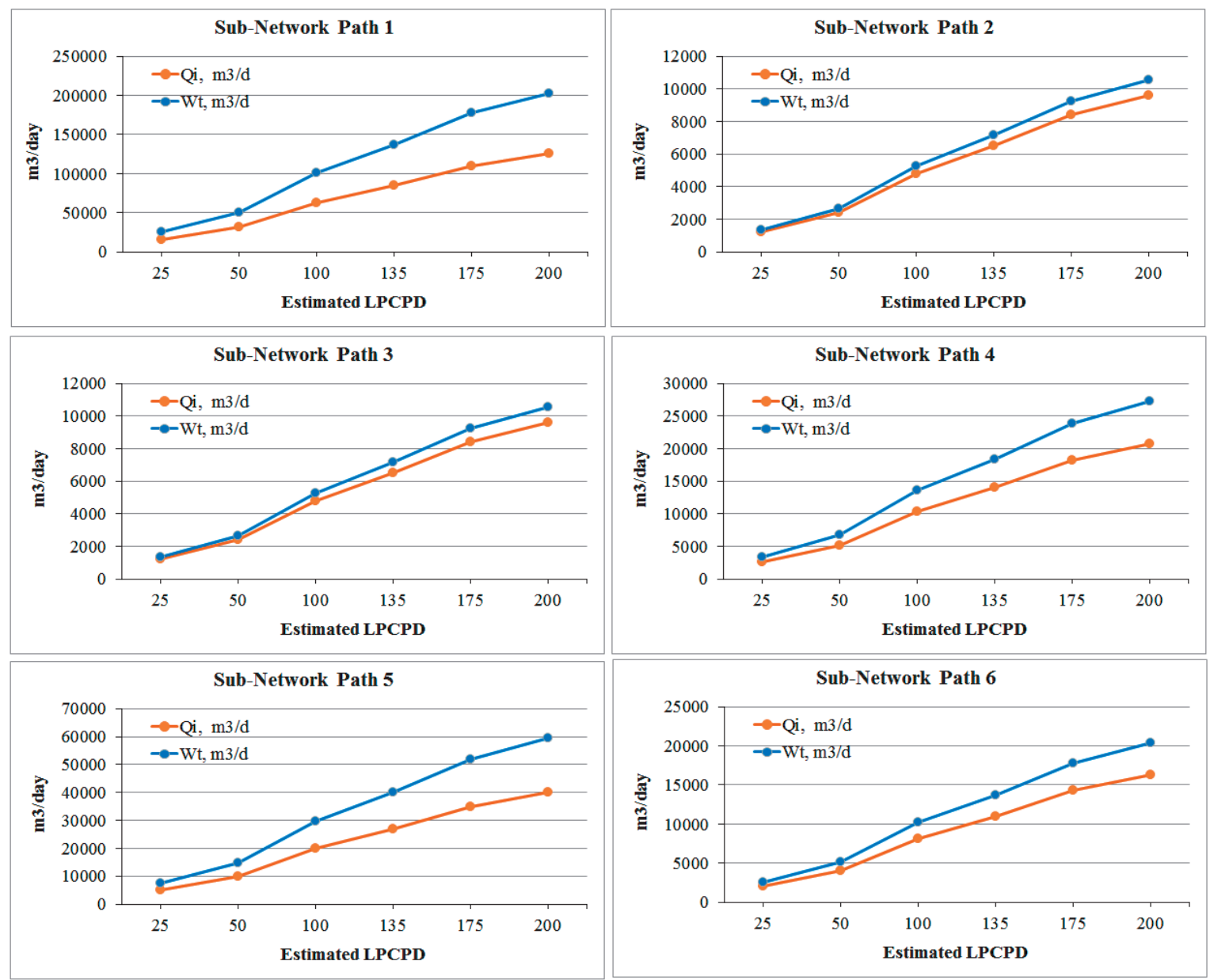

Fig. 4. Variation of Required Water Supply with Water Demand for all subnetwork paths. 
Table 2. Variation of water demands before and after damage.

\begin{tabular}{|c|c|c|c|c|}
\hline \multirow{2}{*}{$\begin{array}{c}\text { Number of Sub-network } \\
\text { Path }\end{array}$} & Normal Supply,Qi m ${ }^{3} / \mathrm{d}$ & \multicolumn{2}{|c|}{ Water Demand, lpcpd from graphs } & \multirow{2}{*}{ Priority Order } \\
\cline { 3 - 5 } & 85000 & Before Damage & After Damage & First \\
\hline 1 & 6500 & 135 & 80 & Fifth \\
\hline 2 & 6500 & 135 & 120 & Fifth \\
\hline 3 & 14000 & 135 & 100 & Third \\
\hline 4 & 27000 & 135 & 95 & Second \\
\hline 5 & 11000 & 135 & 105 & Forth \\
\hline 6 & & 135 & & \\
\hline
\end{tabular}

100 lpcpd which shows that the system needs repair to meet the normal supply.

Subsequently sub-network path 5 is the longest path having node numbers 36, 37, 38, 39, 40, 41, 42, 43, $44,45,46$. The required water supply can be similarly estimated as shown earlier. From Fig. 4, it is observed that for a normal supply of $135 \mathrm{lpcpd}$, which is equal to a total demand of $27,000 \mathrm{~m}^{3} /$ day. The damaged system can meet only 95 lpcpd, showing that the system needs a repair on priority to meet the normal supply.

And sub-network path 6 is also separated from path 1 having node numbers $2,30,31,32,33,34,35$ shows, for a normal supply of water is 135 lpcpd which is equal to a total demand of $11,000 \mathrm{~m}^{3} /$ day. The damaged system can meet only 105 lpcpd showing that the system needs repair to meet the normal supply Fig 4.

\section{Priority Strategy}

In a damaged state, the per capita demand has been calculated in a post-earthquake scenario for each subnetwork path, and these demands are compared with normal demands to establish the priority strategy for improvement of serviceability of the water supply system. This comparison is useful to know whether the supply is sufficient to fulfill the demand and how the serviceability can be improved. The deviation between calculated per capita demand and normal demand will provide a priority of the serviceability requirement of the sub-network path. Among the considered subnetwork path 1 , around $20 \%$ of the zone population and $5(27 \%)$ appears to be the most critical under the post-earthquake condition and needs top priority during the restoration stage. The remaining sub-network path appears to be less affected by the damaging effects.

It is observed from Table 2 below, that sub-network Path 1 is the most damaged, and for a normal supply per capita per day equals 135 Liters which is equivalent to a total demand of $85,000 \mathrm{~m}^{3} /$ day, the damaged system can meet only 80 lpcpd which implies that the system needs a repair on priority basis to meet the normal supply (135 lpcpd). Similarly, the sub-network path 5 seconds most damaged path which needs to be repaired as it meets only 90 lpcpd against a normal supply of $135 \mathrm{lpcpd}$.
Priorities to repair for other sub-network paths will be $4,6,2$, and 3 , as shown in table 2 .

\section{Damage Repair Management}

The repair management has been designed for minimum damage and maximum damage. For damaged sub-network paths, the nodes are repaired sequentially and in increasing order. The repairing process has been assumed to start from the dead-end and the starting end. To demonstrate the damage repair management, the repairing process of sub-network path 5 is considered with a normal supply of 135 lpcpd. The sub-network path contains 11 nodes as shown in Fig 5. To start, the repairing process is triggered by the dead-end (node 46) of this sub-network path considering the minimum damage i.e., 15\% leakage. The sequential improvement in the required water supply as the process of repair nodes proceeds are shown in fig 5 . It can be observed from the figures that as the whole sub-network path gets repaired, the supply becomes normal i.e., $57612 \mathrm{~m}^{3} /$ day. The serviceability improvement using damage repairing processes is shown in fig. 5 for other sub-network paths as well.

The repairing process of sub-network path 5 is also triggered from the first end (node 36) of this subnetwork path considering the maximum damage i.e., $100 \%$ leakage. The improvement in serviceability, the required water supply as the process of repair nodes proceeds, is shown in Fig. 5. As the whole sub-network path gets repaired, the supply is fully restored i.e., $62800 \mathrm{~m}^{3} /$ day. The comparison of repairing process from dead-end and the first end, the repairing process from the first end will ensure a continuous restoration of water supply with increasing repair of nodes which is not seen in repairing process start from dead-end. Also, the required water supply ensured is more in repairing process from the first end.

This study provides the functional reliability of the water distribution system under the post-earthquake scenario for a metropolitan city, Delhi, and repair management to effectively restore the damaged water distribution system. It is based on the model of the Kameda that developed in the pre-and post-earthquake 


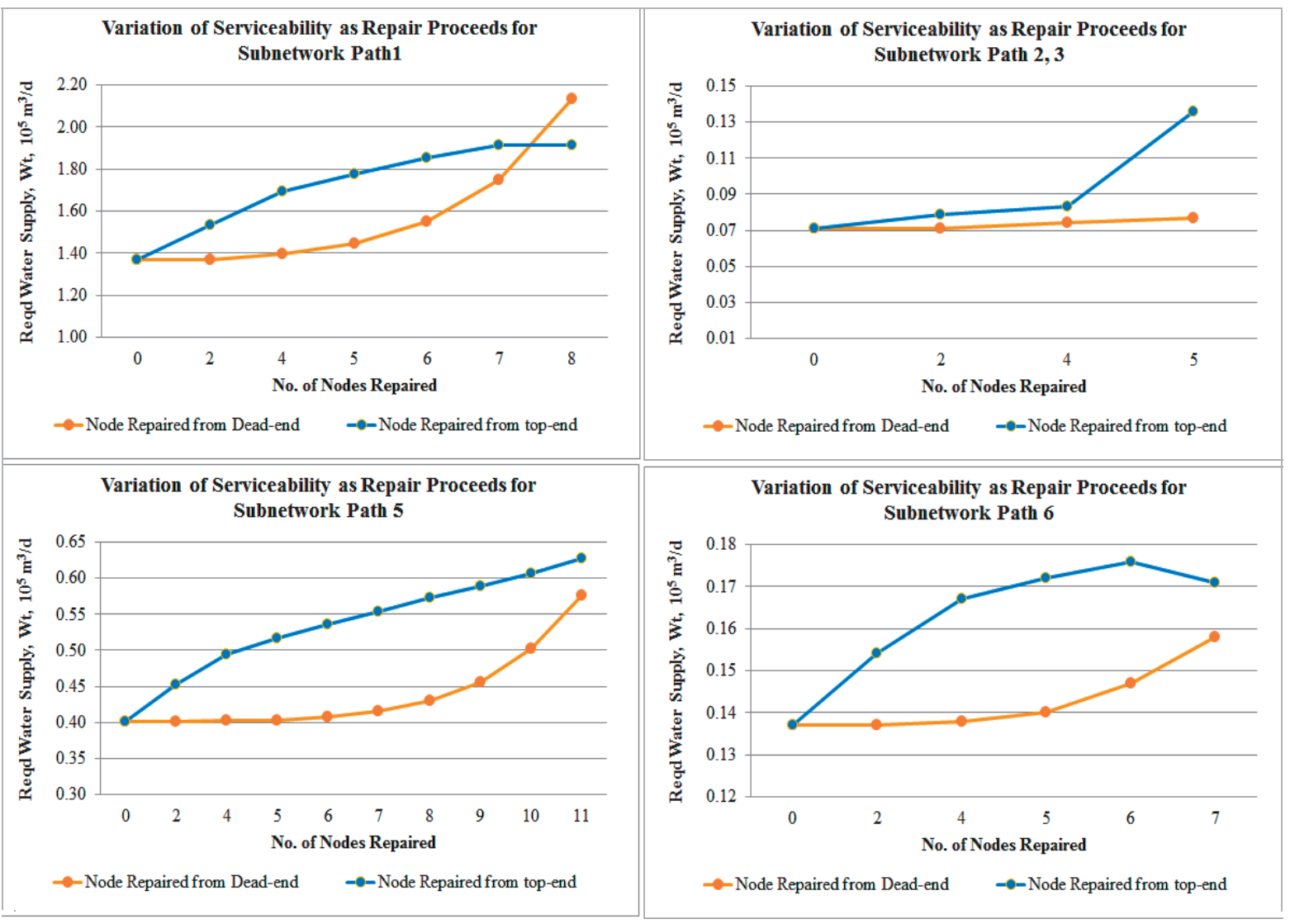

Fig. 5. Variation of Serviceability as Repair Proceeds for Different Sub-network Paths.

scenario to obtain useful information on the behavior of the water supply system. The event modeled is the earthquake that we believe would produce extensive losses to life and property. The priorities strategy for rehabilitation of buried water distribution system is framed considering important factors such as damage in terms of leakage, reliable water demand after earthquake damage, and water distribution path length. As experienced from the studies [34] the extent of loss "during and after" earthquake stage varies in the diversified range i.e., from minimum to complete damage conditions. Hence to cater to the requirement of post-earthquake stages the discharge losses have been simulated in terms of different percentages of actual supply. It is noticed in the sub-network path 1 , that for a normal supply of $135 \mathrm{lpcpd}$, which is equivalent to a total demand of $85,000 \mathrm{~m}^{3} /$ day, the damaged system can meet only $80 \mathrm{lpcpd}$, which implies that the system needs an immediate repair to meet out the normal supply. For sub-network path 2 which is branches from sub-network path 1 . Results for sub-network path 2 and sub-network path 3 are observed that for a normal supply of 135 lpcpd which is equal to a total demand of $6,500 \mathrm{~m}^{3} /$ day, the damaged system can meet a supply of 120 lpcpd near to $135 \mathrm{lpcpd}$, this is due to subnetwork are the shortest one. Hence the system does not need immediate repair to meet the normal supply. To restore the reliable water supply through a water distribution system, repair management is implemented systematically. It can be seen from the outcomes that as the entire sub-network route is repaired, the supply becomes normal.

\section{Conclusions}

In the present study, damage in terms of performance and working of water distribution system after severe earthquakes in a congested metropolitan city is assessed to develop serviceability priorities. A system simulation based on Kameda's model is also developed for obtaining useful information on the behavior of the water supply system in pre and post-earthquake scenarios. The repair management is applied systematically to restore the reliable water supply in a sub-network path. The recommendations are framed and priority of repair and serviceability of the water distribution system of various paths of city zone is established. The per capita demand in the postearthquake scenario for each sub-network path has been calculated using the assumed model and these demands are compared with normal demands to established a priorities strategy for improvement of serviceability. Among the considered sub-network path 1 and 5 appears to be most critical under the post-earthquake condition and needs top priority during the restoration 
stage. The remaining sub-network paths appear to be less affected by the damaging losses. The comparison of repairing process from dead-end and the first end, the repairing process from the first end will ensure a continuous restoration of water supply with increasing repair of nodes which is not seen in repairing process start from dead-end. Also, the required water supply ensured is more in repairing process from the first end. From the repair management analysis, it is observed that with the sequential repairing process of the subnetwork paths, the water supply is fully restored. The present study contributes significantly to understanding the functional reliability of the water distribution system under the post-earthquake scenario that could be used as the preliminary basis by decision-makers, planners, and engineers to better serve their community in an urgent situation. The future scope of the study will focus on geospatial based modeling critical interdependencies with other infrastructure sectors, such as the communication and transportation sector, simulation, and analysis of additional disaster scenarios based on real events and designing or retrofitting networks to improve resilience.

\section{Acknowledgments}

The author thankfully acknowledges the Deanship of Scientific Research, King Khalid University, Abha, KSA, for funding the research grant number R.G.P2/85/41.

\section{Conflicts of Interest}

The authors declare no conflict of interest.

\section{References}

1. NOJIMA N., KAMEDA H., SHINOZUKA M. Fundamental structure of earthquake disaster countermeasures in lifelines. Journal of natural disaster science, 12 (1), 29, 1990.

2. PITILAKIS K., ALEXOUDI M., ARGYROUDIS S., MONGE O., MARTIN C. Earthquake risk assessment of lifelines. Bulletin of Earthquake Engineering, 4 (4), 365, 2006.

3. JEONGWOOK C., DO G.Y., DOOSUN K. PostEarthquake Restoration Simulation Model for Water Supply Networks, Sustainability, 10, 3618, 2018.

4. MARA S., VLAD S.N. Global Climatic Changes, a Possible Cause of the Recent Increasing Trend of Earthquakes Since the 90's and Subsequent Lessons Learnt. Earthquake Research and Analysis: New Advances in Seismology, 21, 2013.

5. RAMAKRISHNAN M., RASTOGI B.K., NARULA P.L., KAMBLE V.P., GUPTA G.D. Workshop on killari earthquake of 30 september, 1993 (held on 24 december, 1993) at hyderabad. Journal of the geological society of india, 43 (5), 613, 1994.
6. Cabinet Office, Government of Japan . White paper on disaster management 2015. Available at. http://www. bousai.go.jp/kaigirep/hakusho/pdf/WP2015_DM_Full_ Version.pdf (Accessed on 19/09/2019).

7. ZHANG L., LIU X., LI Y., LIU Z., LIN J., SHEN J., TANG X., ZHANG Y., LIANG W. Emergency medical rescue efforts after a major earthquake: lessons from the 2008 Wenchuan earthquake, The Lancet, 379, 853, 2012.

8. SITHARAM T.G., VINOD J.S. Nepal Earthquake of April 25, 2015, International Journal of Geotechnical Earthquake Engineering, 6 (1), 81, January-June, 2015.

9. RAMÍREZ-HERRERA M.T., CORONA N., RUIZANGULO A., MELGAR D., ZAVALA-HIDALGO J. The 8 September 2017 Tsunami Triggered by the M w 8.2 Intraplate Earthquake, Chiapas, Mexico. Pure and Applied Geophysics, 175, 25, 2018.

10. MISHRA A.K., ACHARYA S.R. Performance assessment of Salyankot water supply project in post-earthquake scenario of Nepal. J Adv Res GeoSci Rem Sens, 5 (3\&4), 23, 2018.

11. TOMAR A., BURTON H.V. Risk-based assessment of the post-earthquake functional disruption and restoration of distributed infrastructure systems. International Journal of Disaster Risk Reduction, 52, $102002,2021$.

12. LAM C.Y., SHIMIZU T. A network analytical framework to analyze infrastructure damage based on earthquake cascades: A study of earthquake cases in Japan. International Journal of Disaster Risk Reduction, 54, 102025, 2021.

13. HOU G., LI Q. Firefighting capacity evaluation of water distribution system subjected to multi-ignitions of postearthquake fires. Structural Safety, 88, 102035. 2021.

14. RAYAMAJHEE V., BOHARA A.K. Social capital, trust, and collective action in post-earthquake Nepal. Natural Hazards, 105 (2), 1491, 2021.

15. DE IULIIS M., KAMMOUH O., CIMELLARO G.P., TESFAMARIAM S. Quantifying restoration time of power and telecommunication lifelines after earthquakes using Bayesian belief network model. Reliability Engineering \& System Safety, 208, 107320, 2021.

16. MASOOMI H., BURTON H., TOMAR A., MOSLEH A. Simulation-based assessment of postearthquake functionality of buildings with disruptions to crossdependent utility networks. Journal of Structural Engineering, 146 (5), 04020070, 2020.

17. TOMAR A., BURTON H.V., MOSLEH A., YUN LEE J. Hindcasting the Functional Loss and Restoration of the Napa Water System Following the 2014 Earthquake Using Discrete-Event Simulation. Journal of Infrastructure Systems, 26 (4), 04020035, 2020.

18. ADACHI T., ELLINGWOOD B.R. Serviceability of earthquake-damaged water systems: Effects of electrical power availability and power backup systems on system vulnerability. Reliability engineering \& system safety, 93 (1), 78, 2008.

19. YOO D.G., JUNG D., KANG D., KIM J.H., LANSEY K. Seismic Reliability-Based Multi-objective Design of Water Distribution System: Sensitivity Analysis. Journal of Water Resources Planning and Management. 143, 06016005, 2016.

20. ZOHRA H.F., MAHMOUDA B., LUC D. Vulnerability assessment of water supply network, Energy Procedia, 18, 772, 2012.

21. TORPAK S., TASKIN F. Estimation of earthquake damage to buried pipelines caused by ground shaking. Natural Hazards, 40 (1), 1, 2007. 
22. LIU M. Decision Support Framework for Post-Earthquake Restoration of Sewerage Pipelines and Systems, Ph.D. thesis submitted to the Department of Civil and Natural Resources Engineering, University of Canterbury, 2016.

23. YOO D.G., JUNG D., KANG D., KIM J.H., LANSEY K. Seismic Hazard Assessment Model for Urban Water Supply Networks. Journal of Water Resources Planning and Management, 142 (2), 04015055, 2016.

24. KANG D., KIM J.H. Optimal design of water supply networks for enhancing seismic reliability. Reliability Engineering \& System Safety, 146, 79,2016.

25. CHANG Y.H., KIM J.-H., JUNG K.-S. A Study on the design and evaluation of connection pipes for stable water supply. Journal of Korean Society of Water and Wastewater, 26, 249, 2012.

26. WHITMAN R.V., HEIN K.H. Damage probability for a water distribution system. In The current state of knowledge of lifeline earthquake engineering. ASCE, 410, 1977.

27. HALL W.J., NEWMARK N.M. Seismic design criteria for pipelines and facilities. Journal of the Technical Councils of ASCE, 104 (1), 91, 1978.

28. YOO D.G. Seismic Reliability Assessment for Water Supply Networks. Ph.D. Dissertation, Korea University, Seoul, Korea, 2013.

29. DAVIS C.A., O'ROURKE T.D., ADAMS M.L., RHO M.A. Case study: Los Angeles water services restoration following the 1994 Northridge earthquake. In Proceedings of the 15th World Conference on Earthquake Engineering, Lisbon, Portugal, 24, 2012.

30. KLISE K., HART D., BYNUM M., HOGGE J., HAXTON T., MURRAY R., BURKHARDT J. Water Network Tool for Resilience (WNTR) User Manual (No. SAND20209301R). Sandia National Lab. (SNL-NM), Albuquerque, NM (United States), 2020.

31. KLISE K.A., BYNUM M., MORIARTY D., MURRAY R. A software framework for assessing the resilience of drinking water systems to disasters with an example earthquake case study. Environmental modelling \& software. 95, 420, 2017.

32. SYED EMAD A., MOIN K., KHAN R.A. Seismic analysis of building with and without base isolation. Discovery, 39 (179), 122, 2015.

33. SHUKLA A.K., PRAKASH R., SINGH D., SINGH R.K., PANDEY A.P., MANDAL H.S., NAYAL B.M.S. Seismic microzonation of NCT-Delhi. In Proceedings of the Workshop on Microzonation ,39, 2001.

34. KAMEDA H., GOTO H., KASUGA, T. System Reliability and Serviceability of Water Supply Pipelines under seismic Environment. Proc. $8^{\text {th }}$ WCEE San Francisco, 8, 494, 1984. 